\title{
CONTRIBUCIÓN A UNA HISTORIA DE LA POESÍA VENEZOLANA
}

\author{
POR
}

José Ramón Medina

Para una mayoría de autores la poesía venezolana comienza con Andrés Bello (17811865), en la encrucijada de neoclasicismo y romanticismo. Pero hay también quienes señalan mucho más atrás. Por ejemplo, a Juan de Castellanos (1522-1607): "Poeta de las cosas de América, cantor de Venezuela en primer término: el primer poeta, cronológicamente, de nuestra literatura" (Orlando Araujo), en cuya "convivencia de acción y contemplación" encuentra incluso una especie de modelo avanzado de lo que será el escritor de nuestro país. Araujo apunta igualmente - lo que ha hecho también Pedro Díaz Seijas y Roberto Lovera de Sola entre otros- hacia la literatura indígena, pero sin pretender que ella sea el inicio de nuestra poesía. Por su parte, Isaac J. Pardo detecta en Castellanos elementos que apreciaremos luego en Bello: ciertas "pinceladas fuertemente expresivas" del paisaje y, sobre todo, las "largas enumeraciones de frutos del Nuevo Mundo", sin datar tampoco la poesía venezolana de las Elegías (1589) de Castellanos. El mismo Araujo considera la obra de Bello "la primera manifestación exclusivamente literaria" en el país.

Luis Beltrán Guerrero enumera, sin mayor entusiasmo, a otros soldados-poetas del $\mathrm{XVI}$, de quienes no nos queda texto alguno, y se remite a los versos prefaciales de la Historia de la Conquista y población de la provincia de Venezuela (1723) de Oviedo y Baños. Mario Picón Salas, para quien la obra de Castellanos no es sino una de las "malas imitaciones que la epopeya de Ercilla provocó en toda América", aprecia ciertamente al "como poeta idílico" que hay en la Historia, pero sobre todo al narrador fluido, gracioso, ameno. En general se cita a varios autores menores del XVIII y comienzos del XIX, opacados siempre por Bello: Vicente Tejera y Sor María Josefa de los Ángeles (17701818) han llegado a alguna antología, destacándose entre un grupo que incluye fundamentalmente a los frecuentadores de la tertulia de los Ustáriz.

Con Mariano Picón Salas podría sintetizarse el juicio sobre casi toda la época:

Venezuela no tuvo una literatura colonial que pueda compararse, pálidamente, por lo menos por su volumen, con las de México, Perú o Nuevo Reino de Granada .... Los papeles que quedan del siglo XVII y primera mitad del siglo XVIII - novenas y sermones gongorinos o poesías de circunstancias como las que preceden el ya citado libro de Oviedo y Baños- coinciden en su barroquismo colonial con las de las otras partes de América. La misma erudición farragosa, el mismo gusto del retruécano, la misma fórmula altisonante. 
En cuanto a la Venezuela de 1800 , en la que "la alta clase criolla de la ciudad de Caracas alcanza un refinamiento casi europeo", se produce una "poesía neoclásica, juguetona, apacible".

Ya se considere la Venezuela colonial como "un país enteramente salvaje" (Julio Calcaño), ya se rechacen las supuestas "tinieblas coloniales" siguiendo a Mario BriceñoIragorry, los comentaristas son unánimes en señalar la música como la mayor manifestación cultural del período y en hacer de Bello un verdadero gozne entre el final de la Colonia y los primeros decenios en Independencia, cual resumen de lo mejor de ambos momentos.

\section{II}

La gesta libertadora marca, para algunos, otros espantoso vacío cultural. En palabras de Pedro Arismendi Britto: "Ya iniciada la guerra de la Independencia, a excitar a los patriotas que combatían, a cantar sus proezas y a lamentar sus martirios, fue a cuanto estuvo reducido todo el movimiento literario de la época".

Si la literatura propiamente dicha no ha sido revalorizada, sí se ha operado, al menos desde Gil Fortoul, una ampliación del concepto, releyendo ahora en clave literaria los escritos políticos y encontrando en ellos los mejores textos del período: "En los períodos de la Independencia y de la Unión Colombiana, bien puede decirse que el único estilo nuevo es el de Bolívar".

En "Mi delirio sobre el Chimborazo" (1822) y la crítica al poema de Olmedo, "La victoria de Junín" encuentra Gil Fortoul ese "estilo nuevo". Al primero, "fragmento de poesía en prosa brotado en plena forja bélica" (Luis Beltrán Guerrero), lo relaciona Picón Salas con Rousseau y Pedro Grases con "Los sueños" de Quevedo. Por la segunda, Luis Beltrán Guerrero considera a Bolívar "el iniciador de nuestra crítica literaria". El elogio que hace Rafael Ángel Insausti de su "prosa autóctona y personalísima, hecha como para decir de manera que nunca se olviden, los alborozos, dudas, certidumbres y angustias de nuestra América", conlleva la exaltación de Bolívar también como precursor de nuestro romanticismo: "pudo ser en los países que libertara lo que en Francia el creador de Atala y de René: iniciador el más eficaz del movimiento romántico, por la exaltación idealista que sus palabras y sus grandes acciones de diplomacia y de guerra producían". No otra cosa afirma Rufino Blanco Fombona: "la inspiración encendida llega a convertirlo en poeta no ya de acción - que siempre lo fue-sino de la expresión".

La relectura alcanza, hacia atrás, a Francisco de Miranda: "Los diarios mirandinos son, acaso, el más importante hecho literario, en densidad y seducción, de nuestro siglo de las luces" (Gustavo Pereira); insiste en Bolívar como fundador de una verdadera "expresión americana"; se extiende a proclamas, discursos, manifiestos, artículos y otros materiales de combate, sin olvidar "los corridos, décimas, galerones y joropos" en los que Picón Salas rastreaba ya en el siglo XVIII "la sensibilidad criolla", y a los que la guerra "impregnará tanta fuerza épica".

En varios trabajos, Juan Liscano ha desarrollado la trágica disyuntiva que Picón Salas planteara así: "La lucha entre lo popular y lo erudito, entre lo vital y lo académico, será rasgo determinante en nuestra literatura del 800". Con lo que volveremos - siempre-al que, en formula de Picón Salas, "Desde su retiro de Londres ... en los años de la guerra es el único venezolano que ha podido escribir literatura pura": Andrés Bello. 
En el esquema, Bello ocupa por sí solo un período, y lo hace si más vertical que horizontalmente, porque de inmediato se abre otro abismo de contiendas con la Guerra Federal. Si Gonzalo Picón Febres escribe que: " 1830 es la base fundamental e inconmovible de la nación venezolana. Desde ese año ... surgen las mariposas de la literatura, ... las verdaderas delicadísimas estrofas - abejas de brillantes y rubíes- de la poesía nacional", es Andrés Bello el único que nombra como poeta. Hacia 1840: "Ya para entonces había ciudadanos eminentes ... que se daban con entusiasmo verdadero al cultivo de la divina poesía; pero las composiciones rimadas de algunos de estos eminentes ciudadanos ... deben recordarse apenas como una curiosidad bibliográfica e histórica, por su falta absoluta de inspiración y delicadeza artística". Y, en 1846, estalla la guerra: "Las bellas letras cerraron las puertas de su templo", e "impidieron el renacimiento franco de la literatura nacional hasta el año de 64", ya que "la política seguía absorviendo casi por completo la inteligencia de los poetas, de los literatos y de los pensadores".

\section{IV}

Bello marca también cierto eclecticismo en el que predomina lo clásico sobre lo romántico, y que en sus oscilaciones define gran parte de nuestra poesía, y señala sus contenidos: "El tema de la exaltación del agro, del repudio a la ciudad creadora de rencillas y ambiciones, de la contemplación maravillada del paisaje y la flora abundante, inspirará durante años la narrativa y la poesía venezolanas, hasta el punto que debemos a ese impulso algunas de las obras más significativas" (Juan Liscano).

Para Mariano Picón Salas: "Después de Bello y Bolívar no hay mucho que leer" en Venezuela hasta la llegada del modernismo. Retengamos la fórmula lapidaria, antes de perdernos en las etiquetas. Básicamente, se distingue una escuela o tendencia romántica, dividida en dos promociones o generaciones, y una "reacción" o "paréntesis" neoclásico, pero recordando siempre la advertencia de Picón-Febres sobre la inexistencia de movimientos "puros" entre nosotros. Hay quien, como Pedro Díaz Seijas, introduce unos poetas "antecedentes del romanticismo": Antonio Ros de Olano y José Heriberto García de Quevedo. La primera generación romántica la constituyen prácticamente solos, José Antonio Maitín (1804-1874) y Abigaíl Lozano (1821-1866). La segunda incluiría -entre muchos otros- a José Ramón Yepes (1822-1881), el primer José Antonio Calcaño (18271897), Jacinto Gutiérrez Coll (1835-1901), Miguel Sánchez Pesquera (1851-1920) y, como figura máxima, Juan Antonio Pérez Bonalde (1846-1892). Los dos últimos son, también, precursores de la poesía moderna e incluso premodernista el segundo, aunque el romanticismo, nativismo - hasta bien entrado el siglo XX. De ahí una a veces llamada tercera generación romántica, o de transición: Gabriel Muñoz (1864-1908), Andrés Mata (1870-1931), Carlos Borges (1867-1932), Victor Racamonde (1870-1908), Udón Pérez (1870-1926), Sergio Medina (1882-1933) y Juan Santaella (1883-1927), acuñados de diversas maneras según se considere que en ellos predomina el fondo romántico $\mathrm{o}$, ya, el parnasianismo, el modernismo o el nativismo. Entre los neoclásicos tendríamos fundamentalmente a Fermín Toro (1807-1865), Rafael María Baralt (1810-1860) y Cecilio 
Acosta (1818-1881) - aunque a Toro y a Acosta a veces se les considere románticos-y al Calcaño de su última época. Otra clasificación, de índole temática, afirma la existencia de una corriente nativista que se inicia con Bello, pasa por Acosta, Yepes, Pérez Bonalde, Udón Pérez y culmina - pero también comienza o, al menos, se hace visible- con Francisco Lazo Martí (1868-1909) quién, a su manera, logra una conjunción de tendencias similares a la de don Andrés. Se señala igualmente un grupo de poetas "espontáneos y populares".

Nuestra poesía romántica, sobre todo la de la primera generación, ha sido juzgada muy duramente. Por una parte, se considera que, dadas la gesta emancipadora, la personalidad de Bolívar y otros líderes, la situación del país e incluso la sensibilidad criolla, sin olvidar la influencia europea, el romanticismo fue en su momento un movimiento inevitable y necesario, que impregnó además todas las manifestaciones culturales, desde la pintura hasta el vestir. Pero, cuando se llega a la poesía, se la despacha como producto de imitación, falso, lacrimoso, mediocre y ajeno. Es "la mediocre turba romántica" (Gil Fortoul), "un buen período de llantos que terminó por hacer monótona y fastidiosa aquella literatura" (Arismendi Britto), "una escuela desvirtuada de dolor que solloza en las ventanas, de gritos que llenan las alcobas, de dulzura que empalaga y no recrea" (Mario BriceñoIragorry). Las citas serían muchas y coincidentes. Chateaubriand, Lamartine, Hugo, Musset, Byron, Espronceda, el Duque de Rivas y, sobre todo, Zorrilla son mencionados una y otra vez, entre las fuentes literarias que a partir de 1835 empezaron a marcarnos. De las revoluciones románticas francesa y española, escribe Picón-Febres:

procede en línea recta el romanticismo venezolano; pero si aquellas dos revoluciones corrieron paralelamente con el movimiento político-social de ambos países, el romanticismo venezolano nada tuvo que hacer con la política, ni ejerció ninguna influencia sobre ella, ni causó estragos en el seno de la sociedad como en España y en otras naciones europeas, ni fue sino un acontecimiento aislado, parcialísimo, de moda y de pura imitación; y si en Francia y en España el romanticismo constituyó una transformación radical en el arte y dominó todos los géneros literarios y a todos los ingenios, en Venezuela no fue sino parte de una mezcla singular en su literatura y en los hombres mismos que la cultivaron con amor, haciéndola producir flores hermosas y regalados frutos, así como adefesios, extravagancias y delirios. A lo cual debe agregarse que el romanticismo venezolano se nos presenta más visible en la forma que en el fondo, en las calidades extrínsecas que en la sustancia, en el derroche de la imaginación que en la naturaleza de los asuntos que describe.

Picón-Febres exagera el aislamiento cultural de la poesía romántica, así como Julio Calcaño exagera su brevedad ("Duró lo que un relámpago"). Jesús Semprum, que la condena, a la vez la interpreta ligándola a la situación política, como evasión o refugio ante el panorama desconsolador:

Hastiados de aquellas agitaciones aviesas, los hombres de idea principiaron a desesperar de la ventura colectiva y se pusieron a pensar en la individual y propia. El romanticismo fue eso: el aislamiento de las individualidades desencantadas, que buscaban en sí mismas las fuentes de la dicha. 
Semprum resume lo que piensan muchos, de José M. Rojas en adelante. Luis Correa abunda en una explicación que tiene mucho de sicosociológica, entretejiendo el "romanticismo político" de Bolívar con la influencia de Hugo que "daba la pauta en América a los revolvedores entusiastas que aspiraban con un verso a trastrocar el orden social y político de nuestras Repúblicas incipientes", sin olvidar la imponente naturaleza americana y la misma sensación de derrota aludida por Semprum: "bañarse en los últimos resplandores de la epopeya bolivariana y tener que limitar sus ambiciones a la lucha sin gloria y a la intriga sin fortuna" es el drama de "toda la juventud venezolana surgida con la República a las actividades de la acción política y de la inteligencia constructora". De ahí, en la literatura, "la propensión romántica al sollozo, al ímpetu sin dirección y a la fuerza sin equilibrio".

En suma, estábamos condenados al romanticismo. También Picón Salas estima que lo más superficial y fácil de la literatura romántica "hace aflorar en el hombre criollo su tristeza retenida, su sensualidad, su indolencia o ardor voluptuoso .... Lo popular —en nuestras literaturas- encontrará como un cauce y una clave sensible a través de la manera romántica". Y Julio Planchart defiende incluso a Maitín y Lozano porque, sin ellos: "el desenvolvimiento literario de Venezuela hubiera quedado trunco" y, al cabo, "cumplieron el mandato de su época".

Que no lo cumplieran muy bien es otra cosa. Pese a visiones más favorables o siquiera matizadas, una verdadera revalorización del romanticismo en poesía no ha llegado aún a tomar cuerpo, aunque Pedro Pablo Barnola y Gustavo Luis Carrera, desde perspectivas distintas, han propuesto lecturas positivas. Del desprecio crítico se salvan Pérez Bonalde y, en grado menor, Yepes, Calcaño, Gutiérrez Coll y Sánchez Pesquera.

Pero ¿fue mejor nuestra poesía neoclásica? Venida ahora exclusivamente de España como reacción antirromántica; ligada aquí a la creación de la Academia de Ciencias Sociales y de Bellas Letras (1869), a las fiestas centenarias del natalicio del Libertador (1883) y a la "pacificación" impuesta o lograda por Guzmán Blanco, se le considera como una "vuelta al orden" que tampoco dio grandes frutos literarios. Según Julio Planchart, "las generaciones poéticas que llegaron a su plenitud en los años corridos del 60 al 90" tuvieron como modelo las odas neoclásicas de Baralt; en general:

conocían su oficio tal como se entendía entonces y lo ejercían leal y decorosamente. Mas, por la naturaleza misma de la poesía, la cual en su esencia no se deja someter a reglas y nace de disposición un tanto misteriosa y especial del individuo, las obras de aquellos poetas acomodados a las circunstancias dominantes, eran obras de ocasión, y perecederas al cambiar aquéllas.

De hecho, poco queda de toda aquella poesía: Toro, Baralt, Acosta, el Calcaño neoclásico aparecen siempre representados con los mismos textos en las antologías contemporáneas, que ya barrieron las odas a pontífices, academias, inventos y eventos característicos del XIX. Por lo demás, es cierto que esta tendencia -como afirma Díaz 
Seijas - ha sido entendida entre nosotros "en función de lo romántico" y sin estudiarla suficientemente.

VII

1870 ve llegar al Parnaso. Sus miembros, fundamentalmente románticos para la mayoría, podrían ser Jacinto Gutiérrez Coll, Gabriel Muñoz y Andrés Mata, entre los mayores, también Sánchez Pesquera, Racamonde, Santaella, sobre un fondo así descrito por el musicólogo José Antonio Calcaño:

Era época de poesías, que abundaban en todas las ocasiones; nunca había habido en Caracas tantos poetas, buenos, malos y peores. Tenía todo el mundo la fiebre del arte, del ingenio y del saber. Era tiempo de improvisaciones, de juegos de palabras, de juegos de prendas, charadas y adivinanzas, entremezclado todo con alguna pieza de piano.

Si para Jacinto Fombona Pachano, el parnasianismo "entre nosotros presentó un aspecto de seudoclasicismo descolorido y algo ruidoso", se insiste más bien en la tropicalización e incluso el amulatamiento de lo griego, respondiendo a nuestra sensibilidad y también a la situación política. Luis Correa, afirmando la primacía de Gutiérrez Coll como "hierofante de su culto", escribe:

Grecia volvió a ser así para la juventud un grito de combate y una canción de entusiasmo. El culto de sus héroes y el amor de su historia se confundían en una aspiración de libertad.

Era, desde luego, "una Grecia de tercera mano" (Beltrán Guerrero) y "El arraigo de la modalidad parnasiana encontraba un obstáculo insuperable en la falta de ambiente" cultural (Luis León). De todos modos: "apareció una legión de adolescentes prorrumpiendo en himnos dulces y extraños, en canciones de pesadumbre, de refinada lascivia y de brumas sentimentales" (Semprum), en cuya melancolía encuentra el mismo crítico "un signo de inquietud nacional". Como para el romanticismo, pareciera existir una similar necesidad o condena cultural que nos obligaba a ser parnasianos a nuestro modo, con esa mezcla de simbolismo, modelos neoclásicos franceses - Gautier, Leconte de Lisle y, no menos, Heredia - decadentismo, sobre un fondo romántico, ya a la manera del mediterráneo revisitado de Sánchez Pesquera, de los sátiros caribeños de Muñoz, de los valsecitos de Mata o del "schubertismo" - según Picón Salas - de Santaella y Racamonde. Pero la valoración de su poesía ha resultado más justa o favorable. Para Picón-Febres, los rasgos del Parnaso venezolano son:

La serenidad de estatua griega en el conjunto, el aspecto escultural de las estrofas, la opulencia y exquisitez del ritmo, la sabiduría en el manejo del acento y del epíteto, la íntima y estrecha correlación entre las ideas y la forma, la música de los versos y el refinado brillo artístico en el todo de la composición poética.

Para Picón Salas, sus versos marcan cierta "modernidad en la palabra, el tema y el ritmo", mientras que Santiago Key-Ayala considera a los que comenzaron a escribir hacia 
1881 — con poetas como Muños Mata- "la más brillante generación literaria de Venezuela". Disiente, entre otros, Humberto Cuenca, señalando que, pese a sus modelos: "su poesía no tuvo la expresión formal y mesurada, de claridad pacífica y arremansada, que fue característica de aquella lírica apolínea de los franceses".

VIII

Dos programas aparentemente opuestos ven la luz en las páginas de la revista Cosmópolis, en 1894 y 1895 . Uno proclama lo que se llamará criollismo o nativismo; el otro defiende el simbolismo o decadentismo, que aquí vale tanto para el Parnaso como para el modernismo al que se llega casi insensiblemente desde el anterior. Urbaneja Achelpohl es el paladín por antonomasia del primero:

¡Regionalismo! ¡Regionalismo! ... ¡Patria! Literatura nacional que brote fecunda del vientre virgen de la patria .... En la presente cuestión literaria, no sólo está interesada nuestra dignidad, sino la fibra legal de la patria; pues un pueblo que no posee la manera genuina de expresar sus sentimientos no tiene derecho alguno a aspirar a un puesto en la armonía universal.

Aunque Pedro-Emilio Coll sea el más consecuente apologísta del "decadentismo", Pedro César Dominici traza de manera muy sugerente sus contornos:

La decadencia americana, aunque derivada de la decadencia francesa, se diferencia en mucho de ésta: la decadencia francesa sabe a éter y a absintio, la decadencia americana huele a flores y a selvas; en la decadencia francesa predomina el pesimismo, en la decadencia americana todavía existen agonías de optimismo histérico; allá hay más fondo, má 輩as sensualismo, más neurosis; aquí hay más color, más armonía, más tono de luz, más belleza; allá vive el cerebro en constante agitación, la lucha es más terrible; aquí se vive bajo un cielo azul, hay más disgregación de voluntad, más ritmo.

En resumen, el decadentismo americano es "una gran riqueza de imaginación, esfuminada con los colores del cielo tropical".

Urbaneja se refería al "molde de la estética moderna"; Dominici al paisaje; en ese gozne se articulan ambos programas. El nativista o criollista lo cumple Lazo Martí, a partir precisamente de un bagaje modernista. Dada la "Silvia criolla", se relee nuestra literatura en dos direcciones: hacia atrás, hasta llegar a Bello, encontrando también "apuntes", "elementos", rasgos "precursores" de la corriente en Acosta, Yepes, Calcaño, Pérez Bonalde, etc; hacia adelante, pasando por Udón Pérez, Sergio Medina, Alfredo Arvelo, Barrios Cruz, Fombona Pachano, Enriqueta Arvelo, para alcanzar una nueva culminación con Alberto Arvelo Torrealba. El crítico más moledor del criollismo en poesía resulta Jesús Semprum, a contrapelo de una opinión frecuentemente elogiosa:

El criollismo en su esencia sería la pintura de paisajes, tipos y costumbres criollos en un lenguaje especial, también criollo. Y aquí es donde la sediciente secta literaria se tropieza con inconvenientes de más bulto. Muchos han creído que con acudir a palabras indígenas o a las corruptelas y modismos usuales en el vulgo venezolano, se realizaba obra estrictamente venezolana. 
y:

Toda la cacareada poesía criollista se encuentra en la "Silva a la Agricultura" (de Bello). Los nuevos poetas no ha hecho más que glosarla.

En general, se coincide con Semprum en la crítica a los "poetas de segundo orden" que "se dieron a la tarea de especular el tema llanero siguiendo de cerca el estilo de Lazo" (Herman Garmendia), y se rechaza en ellos la repetición inerte de modelos, las excesivas descripciones, los disfraces vernáculos. Pero el mismo Semprum excluía de su rechazo a los mejores - Lazo, Yepes, Udón Pérezó librándolos de la etiqueta escolar: "no pueden, en rigor, considerarse como poetas netamente criollistas". En otro sentido Guillermo Sucre y Francisco Rivera han cuestionado lo modélico de los inventarios del paisaje y del nombramiento de nuestras cosas, operaciones supuestamente obligantes para la poesía latinoamericana, en una crítica que incluye en primer lugar a Bello.

IX

El segundo programa atañe al modernismo y acarrea, como vimos, una atención al paisaje casi similar a la del criollismo. Picón Salas acuñó la fórmula de "parnasianismo criollo" para referirse a nativistas como Udón Pérez; correspondientemente señala como componentes de nuestro modernismo: "Cosmopolitismo literario y por contraste, también nativismo y criollismo". El común fondo o rezago romántico también lo unifica. Por otra parte, las clasificaciones alcanzan quizá su máximo desorden con este movimiento. Muchos de los que hemos encontrado etiquetados como románticos o parnasianos reaparecen ahora: Gabriel Muñoz, Udón Pérez, Andrés Mata, Víctor Racamonde, Juan Santaella, y, desde luego, Pérez Bonalde, aunque en general se les considere "precursores", premodernistas, influenciados por la tendencia o girando en su órbita. La nómina alcanza a Sergio Medina y a Salmerón Acosta (1892-1929) y excluiría, para algunos, a Carlos Borges. Se ignoró hasta hace poco a Salustio González Rincones (1886-1933). Se duda sobre José Antonio Ramos Sucre (1890-1930). La lista más frecuente distinguiría una primera generación modernista, encabezada por Rufino Blanco Fombona (1874-1944) e integrada por Racamonde y Borges; y una segunda, con Santaella, Alfredo Arvelo Larriva (1833-1934), José Tadeo Arreaza Calatrava (1882-1970) y, desde su redescubrimiento, Salustio González Rincones, entre otros autores. Obviamente, también se discute su fecha de aparición, que oscila según los poetas que se considere miembros y según los poemas en que detecten semillas de la escuela; fundamentalmente, el arco se extiende desde 1880, año de edición de Ritmos de Pérez Bonalde, a 1896, con Pentélicas de Andrés Mata, en el que Domingo Miliani sitúa la cristalización del modernismo venezolano. Pero el mismo crítico escribe: "La obra característica de la poesía modernista irá apareciendo ya entrada la primera década del siglo XX".

Usualmente, se saluda esta tendencia como reacción al estancamiento representado por los continuadores tanto del romanticismo como del neoclasicismo. La narrativa y el ensayo correspondientes, marcados por el naturalismo y el positivismo, han ocupado la atención más que la propia poesía, así como los regímenes de Castro y Gómez, durante los cuales, a favor de los cuales y excepcionalmente, contra los cuales se escribe esta literatura. 
De la poesía modernista se ha criticado el esteticismo, la superficialidad, el extranjerismo y el individualismo. También, su aparición tardía, su carácter epigonal y su menor calidad, hondura y renovación formal, comparada con la vertiente narrativa. Incluso uno de sus estudiosos más constantes y comprensivos, Luis Beltrán Guerrero, admite que: "Venezuela no aporta específicamente al modernismo un gran poeta, de la talla de Lugones o de un Valencia", y no digamos ya un Darío. Desde Gonzalo Picón-Febres (para quien esta poesía "es nebulosa, cuasi fantasmagórica, inconsistente, barroca y disolutas", además de contradictoria "con la razón, el buen gusto, con los fines que el arte se propone y con la naturaleza"), hasta Juan Liscano (que la acusa de anacrónica, frustrando incluso "la obra de poetas extraordinariamente hábiles para la versificación" como Arvelo Larriva y Arreaza Calatrava), pasando por Arturo Uslar Pietri ("El modernismo venezolano nunca fue ni muy genuino ni poderoso", exceptuando los dos poetas recién nombrados) no faltan, pues, los juicios negativos. Pero tampoco los positivos, retomando a veces los mismo elementos críticos e invirtiéndolos, tal como hace Santiago Key-Ayala.

También el recalcitrante Semprum aprecia "la crisis renovadora del modernismo", tras "casi diez lustros", según él, en la imitación del palabrero romanticismo español. Mariano Picón Salas, por su parte, ha señalado que en sus mejores libros los modernistas lograron dar un valor propio a lo literario, separándolo de lo político, oratorio o didáctico, y ha relativizado tanto la influencia de Darío como la excesiva exquisitez, apuntando a Blanco Fombona, cronológicamente el primer poeta modernista venezolano, o al menos el primero de cuya pertenencia escolar nadie duda.

Otros argumentos favorables - y la reiteración de los citados- podríamos encontrar en Fernando Cabrices, Paz Castillo, Barnola, Angarita Arvelo, etc. Consideremos, para terminar, un punto de vista reciente, el de Francisco Rivera:

Sensibilización del lenguaje, desacralización de los temas, desenfreno metafórico, una nueva mirada, y la creación de una nueva realidad en el poema, ¿qué más se le podría pedir a nuestro primer movimiento poético?

El modernismo parece languidecer en un mediocre ... posmodernismo. Los mejores reaccionan y superan la herencia, conviertiéndose en generación de 1918 ó 1920. Ramos Sucre rompe el esquema por arriba, declarándose a la vez romántico, simbolista, parnasiano, modernista y posmodernista, cuando no surrealista y, fundamentalmente, él mismo, único y creador, en la síntesis, de su propia tradición y de nuestra modernidad. Salmerón ha quedado flotando entre el modernismo tardío y el 18, así como Leoncio Martínez (18891941) y Pimentel (1890-1942). A Enriqueta Arvelo Larriva (1886-1962) se la incluía entre los del 18 cuando se la creía más joven —nacida en 1901; ahora no se sabe bien qué hacer con ella, aunque por su obra cabría cómodamente - y en buen lugar - en dicha promoción. Luisa del Valle Silva (1902-1962) también ha sido integrada en la misma generación, aduciendo principalmente razones cronológicas; su poesía tiene igualmente puntos de contacto con la del 18 y este argumento es más válido que el de la edad, pues aplicándolo habría que considerar dieciochistas a varios miembros de Viernes. ¿Qué 
importa, por lo demás, la fecha de nacimiento, teniendo en cuenta, por ejemplo, que Job Pim y Ramos Sucre nacen el mismo año? ¿Qué dice eso sobre su poesía?

Hay, sin embargo, un grupo, generación o promoción del 18 o del 20, cuyos miembros indiscutidos son: Fernando Paz Castillo (1893-1981), Enrique Planchart (1894-1953), Luis Enrique Mármol (1897-1926), Andrés Eloy Blanco (1897-1955), Luis Barrios Cruz (1898-1968), Rodolfo Moleiro (1898-1970) y Jacinto Fombona Pachano (1901-1951) como poetas mayores. A ellos añaden argunos comentaristas ya a Ramos Sucre, Enriqueta Arvelo, Luisa del Valle Silva, ya a Alberto Arvelo Torrealba y con mayor frecuencia, Manuel Felipe Rugeles (1903-1959). Pero también a veces a Antonio Arráiz (1903-1962), echando mano a la cronología.

La primera peculiaridad de la generación del 18 es no tener nada fundamental que ver con dicho año, o tener que ver fundamentalmente tanto o tan poco con toda otra serie de años: la fundación del Círculo de Bellas Artes en 1912; la publicación de Primeros poemas de Enrique Planchart en 1919; la premiación del "Canto a España" de Andrés Eloy Blanco en 1923 o la edición, al fin, de los libros inciales de sus miembros -salvo Planchart, Blanco y, si se quiere, Ramos Sucre, que ya habían publicado; y Moleiro y Enriqueta Arvelo, que no lo harían aún- entre finales de los años veinte y comienzos de los treinta. La verdadera manifestación "del 18" ocurre, recitales y tertulias aparte, cuando aparecen esos libros; es decir, cuando ya estaba constituida otra generación, la del 28 o de "vanguardia" y, no menos, cuando se habían hecho presentes Ramos Sucre y Arráiz, quienes de entrada rompen o transforman el modernismo más radicalmente que los "del 18", configurando lo que se ha calificado tentativamente de "prevanguardia". Así, el manoseado "pudor en publicar" de la mayoría dieciochista los convierte en un hecho de lectura retroactiva; de alguna manera la generación posterior los estructura a ellos en cuanto generación propia, y tanto el "prevanguardismo" como el 28 liquidan el modernismo antes que la promoción que se supone haberlo hecho.

¿Qué unifica y qué constituye a Planchart, Paz Castillo, Moleiro, Blanco, etc. en grupo de alguna manera aparte, descartando algunas afirmaciones delirantes? Una cierta mirada al paisaje; la sobriedad expresiva; el idealismo que es su filosofía; la instrumentalización lírica de lo pictórico y lo musical; la inicial influencia de los simbolistas franceses, tamizada por el 98 y algo del 27 españoles; la interiorización de temas y tono; un cultivo relativo de lo folklórico y lo infantil. La enumeración podría seguir pero lo dicho basta para reconocer, en efecto a un grupo, y al mismo tiempo para reducirlo y ampliarlo: Andrés Eloy Blanco desborda el esquema, no digamos Ramos Sucre y Arráiz, y entran en él Enriqueta Arvelo, Rugeles y Luisa del Valle, si a la poesía - no las anécdotas - vamos. Intentar delinear con cierta precisión este contorno - sintetizando, por lo demás comentarios de Pablo Rojas Guardia, Liscano, Beatriz González y el mismo Paz Castillo- no es ignorar en modo alguno la calidad de sus poetas, pero sí relativizar las afirmaciones de quienes pretenden datar nuestra modernidad -o la existencia misma de la poesía del grupo - de los años 1918-1920, operación de índole más mágica que crítica, frecuentemente acompañada de la proclamación de estos poetas como la generación más importante, notable o grande de toda la historia lírica del país. 


\section{$\mathrm{XI}$}

Pero, ¿existe una generación del $18 ? \mathrm{Y}$, si existe, ¿constituye nuestra verdadera vanguardia? También aquí, la datación obedece a hechos extraliterarios como la muerte de Luis Enrique Mármol en 1927 y, sobre todo, la Semana del Estudiante y la aparición del único número de la revista válvula en 1928; son, no obstante, jalones más significativos de los del 18. En cuanto a los miembros, hay poetas que surgen: Luis Castro (1909-1933), Pablo Rojas Guardia (1909-1978), Miguel Otero Silva (1908-1985), Carlos Augusto León (1914) y quizás Alberto Arvelo Torrealba (1905-1971), y luego toda una serie que, perteneciendo en principio al 18, reaparece en esos años. Los libros usualmente considerados como "de ruptura" e inauguradores de una nueva poesía son tres: Poemas sonámbulos de Rojas Guardia, La voz de los cuatro vientos de Paz Castillo y Respuesta a las piedras de Barrios Cruz, todos de 1931. De sus autores, uno es "del 28" y dos son "del 18". Poco después, otros miembros "del 18" se suman a "la vanguardia", aunque sea más o menos fugazmente: Andrés Eloy Blanco y Jacinto Fombona Pachano. De manera que ambas generaciones se manifiestan simultáneamente en libros y acceden juntas a cierta renovación, así como comprartieron las páginas de válvula. Ambas, también, aspiran a que Antonio Arráiz forme parte de sus filas, ya se considere su edad, ya el tipo y significación de su poesía. Paz Castillo, resumiendo la perplejidad cronológica, ha escrito que: "las dos generaciones, por fervores estéticos, por su sentimiento del arte moderno, y por los ideales clásicos que las inspiran, son una misma".

Sin embargo, atendiendo a las obras, es posible que Luis Castro y Rojas Guardia formen, en la época, un núcleo efectivamente renovador, aunque menos de lo que se ha pretendido. El mismo Rojas Guardia caracteriza así al 28:

En la vanguardia venezolana comienza a observarse, desde su aparición, una saludable corriente de fusión de las tendencias más disímiles. Así, hombres que venían del más claro rubendarísmo, poetas de sentido tradicionalista, líricos de expresión paisajista, bardos de empuje totalmente nuevo, que llegaron a escribir con minúsculas, aboliendo la puntuación y colocando sus versos en forma tipográfica como para llegar a dibujar una copa o una flor o la disparatada forma de una nube viajera, se agrupaban con un solo designio: insinuar la protesta y la rebeldía contra el régimen político imperante.

El texto de Rojas Guardia resume la opinión de muchos: es el designio cívico o político el que parece constituir como tal a la generación llamada "de vanguardia", y que amalgama a miembros del $18 \mathrm{y}$ del 28 . Un detallado inventario de circunstancias fuentes, revistas, anécdotas, manifiestos- es lo que suele encontrarse en los estudios al respecto, culminando en el de Raúl Agudo Freites. Juan Liscano, señalando - como Picón Salas - lo tardío de la llegada de los ismos europeos a nuestra costas y considerando ya "muerta" la vanguardia junto con Gómez, en 1935, retrata así su poesía más radical:

Neologismos, barbarismos, alteración de la puntuación, antisentimentalismo, culto al maquinismo, conversión de sustantivos en verbos ... metaforización constante contrastando términos abstractos y concretos ... constituyen algunos de los procedimientos vanguardistas muy pronto convertidos en clisés. 
En cuanto a la calificación "de vanguardia", la discusión sigue abierta pero acentuándose los cuestionamientos. Si Liscano insistió siempre en la importancia de Aspero (1924) de Arráiz, integrando luego a Ramos Sucre - con Ismael Urdaneta tendríamos ya la "prevanguardia" a que nos hemos referido en otros escritos- Beatriz González ha realizado un primer intento de desbrozamiento en la maraña de clasificaciones generacionales y de atribuciones de la invención de nuestra modernidad, proponiendo a su vez - y tentativamente - una primera etapa vanguardista, representada en la década del veinte por Ramos Sucre, Arráiz y el Queremel de Barrio florido, y una segunda etapa en los treinta, con los libros iniciales de Rojas Guardia, Luis Castro, Miguel Otero Silva y Luis Fernando Álvarez: en ambos casos, antes y después del 18. Hacia Álvarez y Gerbasi, miembros de Viernes, apunta también Vilma Vargas para establecer la ruptura en nuestra lírica contemporánea.

Viernes plantea pocos problemas en cuanto a la nómina de sus poetas esenciales: Ángel Miguel Queremel (1899-1939), José Ramón Heredia (1900), Luis Fernando Álvarez (1901-1952), Otto de Sola (1908-1975) y Vicente Gerbasi (1913-1992). Pascual Venegas Filardo (1911) y Óscar Rojas Jiménez (1910) también fueron sus miembros, entre otros. Rafael Olivares Figueroa (1893-1972) y Rugeles formaron parte del grupo, sin que su poesía tenga que ver fundamentalmente con la viernista, aunque la del segundo haya sufrido un relativo y momentáneo contagio, así como la de Rojas Guardia. Pero, descontando la asistencia a la tertulia de 1936 o 1937 en adelante, o la presencia en la lista de colaboradores de la revista de 1939 a 1941, la obra de Viernes - la mayor y más característica- es la de los cinco mencionados. Es patente la fusión intergerencial si se cuenta desde Olivares Figueroa hasta los colaboradores más tardíos como Pálmenes Yarza (1916); se dibuja, en cambio, un arco que cabe en 15 años si se empieza por Queremel y se termina por Gerbasi, aunque la promoción óllamada "del 36" por algunosó se encabalga cronológicamente con la "del 18" y la "del 28".

La poesía viernista ha tenido enemigos y defensores. La antipatía de Picón Salas hacía Viernes se manifiesta con frecuencia. Lo menos que hace es despachar a sus miembros en unas cuantas líneas, refiriéndose a "su contradictoria batalla estética. Contradictoria porque, aparte del desdén por la vieja rima clásica, son entre sí muy diferentes"; o englobarlos en el "enorme río sucio" - mezclado y poderoso- de la influencia de Neruda: "Y está pesando - acaso contra la voluntad de ellos mismo- en esta densa materia de sueños entrecruzados, de sexualidad confusa, de húmedo naufragio de alguno de nuestros poetas", cuya salida "a un sitio limpio" anuncia y saluda. Lo más es dedicarles un retrato satírico:

Hoy algunos poetas confunden la profundidad con la pedantería. Mencional la palabra "trasmundo" y creen que han embotellado el misterio del Universo. Para no parecer románticos se sublevaron definitivamente contra la Luna, pero se fueron a Saturno ... Venezuela les queda muy lejos.

Don Mariano resulta inteligente y fino incluso cuando es injusto. En cualquier caso, he ahí dos de las acusaciones fundamentales: hermetismo y exotismo. En cuanto a Juan 
Liscano, ha ido matizando su opinión - globalmente favorable - desde la polémica que sostuvo con Ulrich Leo en 1943. Entonces escribía:

Imágenes oníricas o brotadas del inconsciente, asociaciones desapacibles e incomprensibles, abertura hacia contemplaciones intelectuales o emocionales abstrusas o abstractas, problemáticas del ser —en realidad de escasa hondura pero que formuladas en un lenguaje tan extraño parecían filosóficas y hasta metafísicas--, desquiciamiento de cualquier orden lógico. Jamás antes, la poesía venezolana había sido sacudida en sus raíces y en su ramazón por una tormenta lingüística semejante.

Reconocía Liscano: "la proposición de un lenguaje y de una expresión de profunda interioridad, de vigilia, de aceptación de la angustia como motivación hacia alguna forma de transcendencia", coincidiendo con lo subrayado por Rafael Olivares Figueroa, y que tiene que ver sobre todo con la poesía inicial del grupo. También: superación del sentimentalismo y el paisajismo; mayor expresividad gracias a lo surreal, onírico, irracional, rompiendo el marco lingüístico y lógico anterior. Por su parte, nosotros hemos subrayado la introducción por el grupo de "una nueva sensibilidad" en la poesía venezolana, mientras otros críticos -por ejemplo, Juan Manuel González- han apuntado que lo mejor de Viernes se produce cuando descubren lo americano, como Gerbasi con Mi padre, el inmigrante (1945), De Sola con En este nuevo mundo (1945) y heredia con Maravillado cosmos (1950).

Finalmente, Ulrich Leo, a quien se consideró en los cuarenta el intérprete de Viernes por sus varios estudios, definió "el surrealismo poético venezolano como un neorromanticismo imbuido de introversión hermética, reacción contra la claridad y gracia, ya vaciada de vida, del modernismo".

\section{XIII}

A Viernes acompaña desde finales de los treinta y comienzos de los cuarenta lo que se ha llamado "reacción antiviernista", uniendo funcionalmente a poetas del 28 como Otero Silva y Carlos Augusto León, decididos cultivadores de "poesía social", con otros que surgían en la época: Juan Beroes (1914-1975), Juan Liscano (1915), Luz Machado (1916), Ana Enriqueta Terán (1919), Aquiles Nazoa (1920-1976), José Ramón Medina (1921), Alarico Gómez (1922-1955) e Ida Gramcko (1924), entre varias docenas de los que Díaz Seijas y nosotros mismo hemos agrupado como generación o promoción del 42, atendiendo no sólo a las fechas de nacimiento sino a una poesía que buscaba modelos en España para alejarse de la exacerbación viernista, aunque alcanzara su propio barroquismo. Se constituyen así generacionalmente miembros de diversos grupos más o menos efímeros: Presencia, Suma, los "universitarios" y Contrapunto, el más estructurado. Desde los clásicos del Siglo de Oro hasta poetas del 98 y el 27 son las fuentes nombradas de una galaxia de autores en la que "se entrecruzan diferentes tendencias" y "la diversidad parece ser su signo más definidor" (Díaz Seijas). Por nuestra parte, hemos propuesto dos rasgos constitutivos de la hornada del 42: 
la vuelta al sentido clásico y universal del ritmo, la medida y la rima, que había sido roto bruscamente por la revolución de vanguardia en 1928, y acentuada después, con características específicas, por los poetas viernistas.

La responsabilidad vital de la vocación y la disciplinada actitud que se orienta hacia una tentativa intensa de la verdad estética, como hecho literario y humano.

Por su parte, Picón Salas se refirió a "un retorno a una más límpida forma tradicional, sin abandonar las conquistas metafóricas y el sentido creacionista de la nueva poesía"; Liscano ha insistido en este discreto eclecticismo como característica mayor; Humberto Cuenca destacó la "opulenta floración de la poesía amorosa" en la década del cuarenta, mientras el grueso de los comentaristas ha señalado elementos como lo social, el humor, cierta carga filosófica, el erotismo, así como el equilibrio entre las formas clásicas y el "gran salto" en el uso de metáforas atrevidas, anotado por Vilma Vargas.

Contemporánea o muy poco posterior a la generación o promoción del 42 , otra serie de autores se manifiesta en la década del cincuenta: Juan Sánchez Peláez (1922), Hesnor Rivera (1928) y Rafael José Muñoz (1928-1981), influidos los dos primeros por el surrealismo del grupo chileno Mandrágora, fundador el segundo del grupo Apocalipsis (1955) en Maracaibo, y el tercero - con Jesús Sanoja Hernández (1920)— creador del efimero Cantaclaro (1950). Muñoz y Sanoja religan la poesía a la política, preanunciando la actividad de los sesenta, y "acrecentaron las posibilidades de nuestro lenguaje poético, destruyendo las compuertas de seguridad levantadas por los condicionamientos tradicionales", racionales y comprensibles (Liscano). En cuanto a Sánchez Peláez, ya sea "el puente indispensable" entre Viernes y la poesía del sesenta, como afirma Liscano; el fundador de la nueva lírica con Elena y los elementos (1951), como dicen —entre muchos otros-Francisco Pérez Perdomo y Gabriel Rodríguez; o quien lleva a su madurez lo ya adelantado por Luis Fernando Álvarez y Gerbasi, según Vilma Vargas, es indiscutible su importancia a manera de gozne entre dos épocas o, si se quiere, dos modos de entender y de hacer la poesía.

\section{XIV}

La generación del 58 o del 60 podría empezar, cronológicamente, con Hesnor Rivera Muñoz, ya que incluye sin dudas a Arnaldo Acosta Bello (1927) y alcanza para algunos a José Barroeta (1924). Sus hechos políticos mayores son la caída de Pérez Jiménez (1958) y la lucha armada contra los dos primeros gobiernos de $\mathrm{AD}$, que se extiende entre 19611962 y la pacificación de la guerrilla en torno a 1968. No hay que olvidar el triunfo de la Revolución Cubana (1959), que tuvo un gran impacto en la izquierda venezolana. Sus hechos culturales se centran en la creación de una serie de grupos, muchas veces editores de revistas y libros, organizadores de exposiciones, e integrados por poetas, narradores, ensayistas, pintores, fotógrafos, cineastas, etc. Entre sus poetas, pertenecieron a Sardio (1958-1961): Ramón Palomares (1935) y Caupolicán Ovalles (1936), además de Guillermo 
Sucre, Edmundo Aray, Carlos Contramaestre, Luis García Morales, etc. A Tabla Redonda (1959-1963): Acosta Bello Rafael Cadenas (1930), con Sanoja Hernández, Jesús Guédez, Ángel Eduardo Acevedo, Darío Lancini, Barroeta. Al Techo de la Ballena (1961 hasta, según se cuente, 1964 o 1968): Francisco Pérez Perdomo (1930), Juan Calzadilla (1933), Caupolicán Ovalles, más otros. A su manera, la revista Zona Franca (1964-1984) conformó un grupo, encabezado por Juan Liscano, con Sucre, García Morales y más tarde Muñoz; también el quincenario En letra roja (1964-1965), entre cuyos colaboradores más jóvenes encontraremos a Luis Alberto Crespo (1941). Desde luego, Trópico Uno (1964) en Puerto La Cruz, con Gustavo Pereira (1940). Cabría mencionar publicaciones - con frecuencia grupales-como: Cal (1962), Lam (1962), En Haa (1963), Sol Cuello Cortado (1964), con Ovalles y Ludovico Silva, $40^{\circ}$ a la sombra (1964), etc., entre las que incluían poetas en roles protagónicos. Alfredo Silva Estrada (1933) se mantuvo al margen de las diversas formaciones, aunque editó en París la revista Señal (1957). Eugenio Montejo (1938) y -ya fuera de los límites generacionales-Reynaldo Pérez Só (1945) han estado ligados a las revistas Zona tórrida y Poesía, a partir de los setenta, y se les engloba en un llamado "grupo de Valencia".

La consideración de ese abigarrado panorama interesa, aquí, en la medida en que define o marca la producción poética. Alfredo Chacón, Ángel Rama, Lubio Cardozo, José Barroeta, Jesús Sanoja Hernández y, como gran polemista, Juan Liscano, han entregado suficiente material para una caracterización en conjunto y en detalle, tanto literaria y cultural como socio-política, sin olvidar otros aportes: Vilma Vargas, las encuestas de Mary Ferrero. Intentemos, pues, un relativo deslinde.

El sartrismo a la moda, lo elitesco, la rebeldía individualista, el rechazo del "color local", un reformismo modernizador y mimético, cierto idealismo y el seguir girando en la órbita cultural francesa son rasgos apuntados por Rama y Chacón respecto a Sardio, del que Barroeta señala el insuficiente compromiso político, que llevará a la crisis.

Tabla Redonda parece ser un marco más definitorio para sus poetas, ligados - como los demás miembros- de alguna manera al PC. Marxismo y militancia, revisión del pasado, literatura relacionada con el cambio social pero en la que "lo político nunca llega a privar sobre lo creativo", apunta Barroeta. Jesús Sanoja Hernández, a quien se suele considerar cabeza teórica del grupo, ha distinguido Tabla Redonda de Sardio según sus preferencias literarias: lo que para éste representaban Perse, Beckett, Kafka, Proust, lo eran para aquél Vallejo y Neruda, Brecht, el realismo mágico. Ambos críticos señalan que se quería hacer del lenguaje un arma contra lo burgués, pero sin plantearse radicalmente la subversión de la escritura; en palabras de Sanoja: "hubo más cuidado (que en el Techo de la Ballena) en no hacer sinónimos violencia política y lenguaje poético caótico". O, para Liscano, el grupo: "tuvo una actitud más ordenada, más respetuosa de las jerarquías estéticas y lingüísticas".

El Techo de la Ballena, surgido en parte de la disolución de Sardio, se distinguió por su violencia, espíritu anárquico, voluntaria agresividad, provocación instrumental, de índole dadaísta y surrealista, funcionando "como equivalente literario y artístico de la violencia armada venezolana de la época betancourista" (Rama) o como "una especie de guerrilla surrealista contra el cadáver cultural de la burguesía" (Chacón). Sanoja relativiza su carácter revolucionario: "lo que se generalizó fue la forma, no la actitud, violenta". Liscano insiste 
en la contradicción entre escritura y acción, apreciando su "aventura literaria creadora, liberadora, definitivamente favorable a la expansión lírica". Rama subraya la modernidad alcanzada por nuestra literatura con el Techo, mediante la exploración de lo feo, las basuras, lo necrofilico, lo urbano, así como la experimentación cuestionadora del propio quehacer artístico. Si Calzadilla y Pérez Perdomo son para él "los dos poetas centrales del movimiento" - siendo Calzadilla, según Lubio Cardozo, el más destacado- un libro como Duerme Ud. Señor Presidente? (1962) de Ovalles, es también muy representativo de la "guerrilla" ballenera.

Zona Franca no define la poesía de Liscano ni En letra roja la de Crespo. Tropico Uno, con Pereira, es para Sanoja "donde el léxico se hizo más cargado, más político y crudo" en el lapso 1962-1964, en que la poesía joven "adquirió cierto aire de familia, un parentesco de léxico y una momentánea unidad intencional". A partir de 1964, comienza la desintegración grupal y se subrayan las trayectorias individuales, que en algunos casos no han sido más que desarrollos de lo adquirido entonces y que nunca dejan de mostrar, de diversa manera, la huella original.

Más allá de la valoración de autores y obras, o de la crítica o el elogio a su actitud política, se ha apreciado en la promoción del 58 y del 60: "La tentativa modernizante, universalista, de ruptura más radical sufrida por la poesía venezolana y, en general, por su literatura" (Liscano); "el signo de la madurez posible" en nuestra lírica (Gabriel Rodríguez); una de las producciones poéticas "más importantes y prolíferas que hemos tenido hasta ahora" (Vilma Vargas); nuestra entrada - tardía - en la modernidad (Rama). Fuera ya de sus inicios grupales, se han propuesto diversas clasificaciones de una poesía sobre cuya heterogeneidad se insistó mucho en polémicaś que ya tienen veinte o casi treinta años, pero de la que cabe reconocer una fundamental unidad, por debajo de las voces individuales. Juan Liscano, Guillermo Sucre, Alejandro Oliveros, Vilma Vargas, Armando Rojas Guardia han ofrecido esquemas que cabría sintetizar, distinguiendo según el mayor o menor "formalismo", "textualismo" o "trascendentalismo" (Cadenas, Silva Estrada como ejemplos); una corriente de "subversión" lingüística y política (Caupolicán Ovalles, Calzadilla, Pereira, Valera Mora); una más onírica o surrealizante (Pérez Perdomo, también Acosta Bello, Hesnor Rivera); una "telúrica" (iniciada por Palomares, seguida por Crespo). A esta rejilla de utilidad relativa se añaden otros elementos, ya se considere el poema en prosa (Pérez Perdomo, Cadenas, Acosta Bello) o en verso; los temas (poesía urbana: Calzadilla Pereira; política: Ovalles, Pereira, Valera Mora; los ritos mágicos y sueños: Pérez Perdomo; la tierra y la infancia: Palomares, Crespo; y así sucesivamente); o se distinga — con Liscano- una interiorización que conlleva el abandono de lo político y preocupaciones "espirituales" u "ontológicas", pero en la que es preciso separar también los poetas del "despojamiento" como Montejo, Pérez Só, y los de la violencia escritural como Muñoz.

La obra de las generaciones posteriores, con voces destacadísimas como las de Yolanda Pantin, Rafael Arráiz Lucca, Igor Barreto, Miguel Márquez, Márgara Russoto, María Clara Salas y varias docenas más: un proceso demasiado cercano como para sintetizar ya la crítica al respecto e incluirla en este esquema histórico. 